\title{
Corrigendum
}

\section{New heuristic for the dynamic layout problem}

E Erel $^{1}$, JB Ghosh ${ }^{2}$ and JT Simon ${ }^{3}$

${ }^{I}$ Bilkent University, Turkey; ${ }^{2}$ University of Southern California, USA; and ${ }^{3}$ State University of New York at Geneseo, USA

Journal of the Operational Research Society (2005) 56, 1001. doi:10.1057/palgrave.jors.2601978

Correction to: Journal of the Operational Research Society (2003) 54, 1275-1282. doi:10.1057/palgrave.jors.2601646

A few of the results for the 15- and 30-department problems (Tables 2 and 3) reported by us in our paper ${ }^{1}$ were incorrect (because of certain typographical errors in the input data). The correct results have now been obtained and differ from the incorrectly reported ones only slightly; some of the new results actually represent an improvement. Encouraged by the interest of other researchers in our detailed results, we have also constructed a website (http://bilkent.edu.tr/ erel/ dynlayout.html) so that one can easily download, for all relevant problem instances, the best layout in each period and the associated cost found by us.

\section{References}

1 Erel E, Ghosh JB and Simon JT (2003). New heuristic for the dynamic layout problem. J Opl Res Soc 54: 12751282. 